\title{
EGU21-2739
}

https://doi.org/10.5194/egusphere-egu21-2739

EGU General Assembly 2021

(c) Author(s) 2021. This work is distributed under

the Creative Commons Attribution 4.0 License.

\section{Lithospheric structure of the Iberian Central System (Iberian Massif) imaged by the wide-angle seismic reflection/refraction CIMDEF experiment}

\author{
Irene DeFelipe ${ }^{1}$, Puy Ayarza², Imma Palomeras², Juvenal Andrés ${ }^{1,3}$, Mario Ruiz ${ }^{1}$, Juan Alcalde ${ }^{1}$, \\ David Martinez Poyatos ${ }^{4}$, Francisco Gonzalez-Lodeiro ${ }^{4}$, Mariano Yenes ${ }^{2}$, Montserrat Torne ${ }^{1}$, and \\ Ramon Carbonell \\ ${ }^{1}$ Geosciences Barcelona, GEO3BCN-CSIC, Barcelona, Spain \\ ${ }^{2}$ Department of Geology, University of Salamanca, Salamanca, Spain \\ ${ }^{3}$ Institut Catogràfic i Geològic de Catalunya, Barcelona, Spain \\ ${ }^{4}$ Department of Geodinamics, University of Granada, Granada, Spain
}

The Iberian Central System represents an outstanding topographic feature in the central Iberian Peninsula. It is an intraplate mountain range formed by igneous and metasedimentary rocks of the Variscan Iberian Massif that has been exhumed since the Eocene in the context of the Alpine orogeny. The Iberian Central System has been conventionally interpreted as a thick-skinned popup mountain range thrust over the Duero and Tajo foreland basins. However, its lithospheric structure and the P-wave velocity distribution are not yet fully resolved. In order to place geophysical constraints on this relevant topographic feature, to identify lithospheric discontinuities, and to unravel the crustal deformation mechanisms, a wide-angle seismic reflection and refraction experiment, CIMDEF (Central Iberian Mechanism of DEFormation), was acquired in 2017 and 2019. It is a NNW-SSE oriented 360-km long profile that runs through the Duero basin, the Iberian Central System and the Tajo basin. First results based on forward modeling by raytracing show an irregularly layered lithosphere and allow to infer the depth extent of the northern Iberian Central System batholith. The crust is $\sim 31 \mathrm{~km}$ thick under the Duero and Tajo basins and thickens to $\sim 39 \mathrm{~km}$ under the Iberian Central System. A conspicuous thinning of the lower crust towards the south of the Iberian Central System is also modeled. Along this transect, a continuous and high amplitude upper mantle feature is observed and modeled as the reflection of an interface dipping from 58 to $62 \mathrm{~km}$ depth featuring a P-wave velocity contrast of 8.2 to $8.3 \mathrm{~km} / \mathrm{s}$. Our preliminary results complement previous models based on global-phase seismic and noise interferometry and gravity data, provide new constraints to validate the accuracy of passive seismic methods at lithospheric scale, and contribute with a resolute P-wave velocity model of the study area to unravel the effect of the Alpine reactivation on the central Iberian Massif.

This project has been funded by the EIT-RawMaterials 17024 (SIT4ME) and the MINECO projects: CGL2016-81964-REDE, CGL2014-56548-P. 